\title{
PROFESSOR DE EDUCAÇÃO FÍSICA: ESTÁS SATISFEITO COM TUA PROFISSÃO?
}

\author{
Felipe Tavares Ribeiro ${ }^{1}$ \\ Suelen Moreira ${ }^{2}$ \\ Rafael Gonzalez Bastos ${ }^{3}$ \\ Leonel Godinho da Silva Junior ${ }^{4}$ \\ Cristiano Ollé Pereira ${ }^{5}$ \\ Cesar Moraes de Souza ${ }^{6}$
}

RESUMO: O objetivo deste estudo foi o de investigar a relação do professor de Educação Física com seu trabalho no cotidiano da escola, abordando as condições de satisfação e de insatisfação com o exercício de sua profissão. Participaram da investigação 13 professores de Educação Física que atuam na Secretaria Municipal e Coordenadoria Estadual de Educação da cidade de Pelotas - Rio Grande do Sul (Brasil). A metodologia utilizada fundamentou-se na abordagem qualitativa. $O$ instrumento de coleta de informações foi uma entrevista semiestruturada e as respostas foram gravadas em áudio, a partir do consentimento dos entrevistados. A interpretação das informações seguiu a metodologia da análise de conteúdo. Analisou-se a importância do esporte como conteúdo da Educação Física e do trabalho docente em si, juntamente com as relações escolares do dia-a-dia, como a relação professor-aluno e professor-colegas de trabalho, reconhecimento do trabalho realizado, condições, ou seja, infraestrutura, materiais, carga horária, salários, formas de disciplina dos alunos.

Palavras-chave: Escola. Educação Física. Satisfação Profissional Docente.

\section{INTRODUÇÃO}

Observa-se que os estudos sobre a satisfação profissional têm sido a preocupação de autores em várias áreas do conhecimento, entretanto, ainda é escasso o número de pesquisas sobre essa problemática junto à Secretaria Municipal e a Coordenadoria Estadual de Educação da cidade de Pelotas - Rio Grande do Sul (Brasil), em especial, na área da Educação Física.

A condição de formanda do curso de Licenciatura em Educação Física, prestes a entrar no mercado de trabalho, instigou-me a averiguar a satisfação com o exercício da profissão de professores de Educação Física no âmbito escolar público, uma vez que esse é

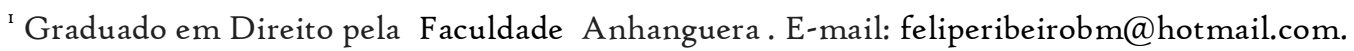

2 Graduada em Educação Física. - Escola Superior de Educação Física pela Universidade Federal de Pelotas .

${ }^{3}$ Engenheiro Civil Empresarial pela Universidade Federal do Rio Grande.

${ }^{4}$ Tecnologia em sistemas para internet. Instituto Federal do Rio Grande do Sul.

${ }^{5}$ Graduado em Educação Física pela Universidade Federal de Rio Grande -FURG - Rio Grande.

${ }^{6}$ Graduado de Engenharia Mecânica Universidade Federal de Rio Grande - FURG.
} 
um dos principais ambientes de atuação desse profissional.

A satisfação profissional neste trabalho é compreendida como:

[...] um conjunto de sentimentos favoráveis ou desfavoráveis com os quais os empregados vêem seu trabalho (...) como qualquer outra atitude, é geralmente formada durante determinado período de tempo, na medida em que o empregado vai obtendo informações sobre o ambiente de trabalho. (MORETTI, s.d, p. 9).

O problema investigado foi o da relação do professor de Educação Física em seu trabalho no cotidiano da escola, abordando as condições de satisfação e de insatisfação com o exercício de sua profissão. Assim, a pergunta que orientou este estudo foi: dadas as condições de trabalho existentes na escola pública, o professor de Educação Física está satisfeito com sua profissão?

O estudo buscou averiguar o nível de realização profissional de professores de Educação Física na prática escolar, em algumas escolas municipais e estaduais da cidade de Pelotas, localizadas na região sul do Estado do Rio Grande do Sul (Brasil). De forma mais específica, procurou-se identificar a satisfação profissional dos professores relacionada às condições de trabalho e às relações sociais estabelecidas no ambiente profissional.

Tendo em vista algumas abordagens teóricas e das investigações desenvolvidas em torno da questão da satisfação profissional docente, definiram-se as seguintes hipóteses: a situação dada no âmbito escolar para a intervenção docente é geradora de processos que levam o professor a construir relações de realização com o seu trabalho; ou frustração ou, ainda, existem fatores que provocam tanto satisfação como insatisfação.

Acreditamos que foi de extrema relevância a compreensão deste fenômeno junto à rede municipal e estadual, pois permitiu conhecer a realidade escolar e seu cotidiano, tais como: condições de trabalho, as relações interpessoais que se estabelecem dentro desse espaço, características dos alunos, entre outros.

Desse modo, o estudo contribui não só para a reflexão acerca da satisfação profissional docente como também para a discussão da necessidade de ações que garantam condições adequadas de trabalho para os professores envolvidos.

As pesquisas que procuram averiguar o sentimento dos professores quanto ao seu exercício profissional "trazem à tona elementos importantes para se discutir qualidade no ensino, elementos estes que, em geral, são desconsiderados pelas políticas educacionais" (GATTI, 1997, p. 62-63). Para Hargreaves e Fullan (200o) apud Lapo (2008, p.3) é importante averiguar as fontes de satisfação do trabalho para que estas possam servir de 
auxílio no enfrentamento das dificuldades encontradas no exercício do magistério.

Os sujeitos da pesquisa foram os professores de Educação Física que atuam na Secretaria Municipal e Coordenadoria Estadual de Educação da cidade de Pelotas (RS) e que aceitaram participar do estudo, assinando o termo de consentimento de livre esclarecimento.

Participaram 13 professores, 8 do sexo feminino e 5 do sexo masculino, dos quais: ıo lecionam em escolas do município, 7 em escolas do estado e 3 ainda possuem emprego no setor privado, em que o período de exercício da docência varia de 5 a 30 anos de serviço para ambos os sexos e com carga horária igual ou superior a 20 horas semanais, em alguns casos atingindo quase 6o horas semanais. Todos possuem formação em Educação Física da Universidade Federal de Pelotas, tendo como maior influência ao ingresso no curso, o esporte.

As escolas participantes da pesquisa foram aquelas que seus dirigentes permitiram a realização do estudo. Primeiramente foi feito um contato com as instituições a serem pesquisadas e o próximo passo foi o contato direto com os professores para apresentar o projeto e convidá-los a participar do mesmo.

As informações foram coletadas por meio de uma entrevista semiestruturada, cujo roteiro tratou sobre a satisfação profissional dos professores de Educação Física atuantes no âmbito escolar público. Para manter e captar de forma autêntica, as respostas foram gravadas em áudio a partir do consentimento dos entrevistados.

As entrevistas foram realizadas em dia, hora e local combinados previamente pelo entrevistador e entrevistado. $O$ tratamento aos dados procedeu-se da seguinte maneira: transcrição e leitura das entrevistas; organização das categorias, identificação dos núcleos de sentido; realização dos procedimentos para compreender e interpretar os dados empíricos, articulando-os com a teoria que fundamentou o estudo.

O estudo caracteriza-se como uma pesquisa qualitativa, pois, como salienta Minayo (2007, p.2I), lida com um nível de realidade que não pode ou não deve ser quantificado, qual seja, o dos valores e das atitudes.

Assim, segundo a autora (p. 26), a pesquisa qualitativa pode ser dividida em três etapas, as quais foram seguidas neste estudo: $\mathrm{I}^{\mathrm{a}}$ etapa; fase exploratória, que consistiu "na produção de pesquisa e de todos os procedimentos necessários para preparar a entrada de 
campo"; $2^{\text {a }}$ etapa; trabalho de campo, consistiu "em levar para a prática empírica a construção teórica elaborada na primeira etapa". Nesta fase foi aplicado o instrumento para coleta de dados, ou seja, a entrevista semiestruturada; $3^{\underline{a}}$ etapa; análise e tratamento do material empírico e documental que diz respeito ao "conjunto de procedimentos para valorizar, compreender, interpretar os dados empíricos, articulá-los com a teoria que fundamentou o projeto" (MINAYO, 2007: 26-27).

Para a análise dos dados obtidos com a pesquisa, utilizou-se o Método de Análise de Conteúdo no qual é definido como um

[...] conjunto de técnicas de análise das comunicações visando obter, por procedimentos sistemáticos e objetivos de descrição do conteúdo das mensagens, indicadores (quantitativos ou não) que permitem a inferência de conhecimentos relativos ás condições de produção/recepção (variáveis inferidas) destas mensagens. (BARDIN, 1979, p. 42 apud MINAYO, 2007, p. 83).

\section{CAPÍTULO I: SATISFAÇÃO PROFISSIONAL: O QUE DIZEM OS ESTUDOS?}

A temática satisfação profissional de professores de Educação Física tem sido objeto de estudo cada vez mais freqüente nos últimos anos por investigadores. Os resultados vêm indicando que há um conjunto de fatores que determinam o sentimento de satisfação e insatisfação nos professores quanto ao exercício da profissão.

Analisar o nível de (in) satisfação profissional e seus fatores determinantes foi objeto de estudo de Folle et. al. (2008) com 54 professores de Educação Física da Educação Infantil de duas Secretarias Municipais do Estado de Santa Catarina (SC).

Os professores dessa pesquisa manifestaram que fatores pedagógicos e fatores relacionais influenciam positivamente para a satisfação profissional. Quando se referem ao determinante pedagógico, os motivos para a satisfação foram a motivação demonstrada pelos alunos durante as aulas e os resultados positivos do processo ensino-aprendizagem. Nos relacionais, sobressaiu-se o bom relacionamento com os alunos e a socialização com os colegas de profissão.

Por outro lado, os docentes demonstraram insatisfação com o trabalho educativo pelos seguintes fatores: desvalorização social da profissão, o não reconhecimento pelo exercício docente, as condições materiais e estruturais inadequadas para as aulas de Educação Física, a instabilidade profissional e a falta de investimento público na educação.

Em outro estudo denominado "o professor de educação física escolar no ensino fundamental: análise da realidade na cidade de Meleiro, SC”, realizado por 
Conceição et. al. (2009), para conhecer o perfil da vida profissional do professor em escolas de ensino fundamental das redes de ensino público e neste, os dados apontaram resultados semelhantes ao do estudo do Folle et. al. (2008).

Os professores estudados referiram-se à afetividade e convívio com os alunos como principais motivos para o sentimento de satisfação com a docência na escola. De acordo como o estudo de Folle et. al. (2008), também foi constatado que os professores manifestam insatisfação à profissão por conta das condições de trabalho (falta de estrutura física e material de Educação Física para trabalhar) e da desvalorização com a profissão. Ainda, outros motivos foram mencionados como o baixo salário e a pouca participação do aluno nas aulas.

Dados semelhantes também foram observados na pesquisa feita por Krug (2008) com professores de Educação Física do ensino fundamental da rede pública de Santa Maria (RS), que objetivou analisar se vale a pena ser professor de Educação Física escolar.

O estudo chama a atenção para o fato dos professores entrevistados relatarem que a relação estabelecida entre professor e aluno é a única razão para a satisfação no trabalho. Por outro lado, para o sentimento de insatisfação, houve vários motivos, tais como: o baixo salário, a desvalorização da Educação Física escolar, as precárias condições de trabalho pela falta de espaço físico adequado à prática da Educação Física, e a falta de materiais para trabalhar.

A pesquisa também constatou outros dados, os quais não foram encontrados nas investigações anteriores para a insatisfação. Um deles vinculou-se à indisciplina dos alunos e, o outro, ao relacionamento com os colegas de trabalho, diferente do estudo de Folle et. al. (2008).

Nesse grupo, os docentes declararam, em sua quase totalidade, estarem insatisfeitos pelo relacionamento com seus colegas de serviço. O descontentamento é decorrente do convívio com os mesmos, pois a divergências de opiniões causa atritos, inimizades e a formação de grupos isolados de professores que rejeitam os demais.

Em outra pesquisa, realizada por Silva e Krug (2007), no qual buscaram identificar os motivos para o sentimento de satisfação e insatisfação dos professores de Educação Física das escolas municipais, estaduais e particulares, de algumas cidades localizadas na região central do Estado do RS (Brasil), os dados encontrados também não se 
diferenciaram em sua quase totalidade, dos obtidos nos estudos citados anteriormente.

Os professores manifestaram que a satisfação quanto ao exercício profissional está também ligada à afetividade com os alunos, o aprendizado dos mesmos e o convívio na escola. Entretanto, diferente dos outros estudos, a competição, o conteúdo esportivo da Educação Física e a liberdade dos professores definida pela pouca ou nenhuma orientação pedagógica da escola, também apontaram para o bem-estar profissional do professor.

Para o sentimento de insatisfação com a profissão, ainda observaram a falta de espaços físicos e materiais, a desvalorização da Educação Física, a indisciplina dos alunos, o baixo salário e o conflito com os colegas. Foram mencionados outros fatores os quais não apareceram em outras pesquisas; são eles: a competitividade que o sistema exige e a dificuldade de alguns alunos. Houve, inclusive, relatos que indicaram não haver nenhum motivo causador de desagrado pela profissão.

\section{CAPÍTULO II: A EDUCAÇÃO FÍSICA E A SATISFAÇÃO COM O EXERCÍCIO PROFISSIONAL}

Os professores de Educação Física da Secretaria Municipal e Coordenadoria Estadual de Educação da cidade de Pelotas - RS (Brasil), que participaram desta investigação, manifestaram diferentes posicionamentos quanto à satisfação/insatisfação no exercício docente. Para a satisfação, diversos são os motivos que apontam para esse sentimento.

Alguns motivos mencionados pelos entrevistados revelaram as relações escolares no dia-a-dia como fator de satisfação profissional. $O$ mais constante vincula-se à relação professor-aluno, reforçando os resultados encontrados nos estudos de Folle et. al. (2008), Conceição et. al. (2009), Krug (2008), Silva e Krug (2007). Todos os professores declararam estarem satisfeitos por conta da afetividade dos alunos.

[...] costumo dizer que a relação com os alunos é a melhor coisa que têm[...] (Professora or).

[...] é muito cansativo esse trabalho com os alunos da escola, mas eu adoro por que eles te dão um retorno a cada dia, sabe, isso é que faz a gente, eu ser uma apaixonada porque com todos esses problemas eu chego lá na sala de aula e eles tão lá me esperando "professor o que é que a gente vai fazer hoje" [...] tenho satisfação por isso [...] pelos alunos [...] (Professora 03).

Uma das características do trabalho docente é a relação estabelecida entre professor e aluno. Para Codo (1999) o trabalho só é efetivo e atinge os objetivos 
estabelecidos quando se estabelece uma relação afetiva.

Para o autor, o objetivo do docente é a aprendizagem dos alunos. Para que a meta seja alcançada, vários fatores são necessários, como a "capacidade intelectual e vontade de aprender por parte do aluno, conhecimento e transmissão de conteúdo por parte do professor, apoio extraclasse por parte dos pais”, entre outros. Entretanto, considera que existe um que funciona como um catalisador desse processo: a afetividade. "É mediante o estabelecimento de vínculos afetivos que ocorre o ensino-aprendizagem“ (p.5o).

Siqueira (2004) também afirma que a existência da afetividade e do respeito na relação entre professor e aluno contribui para que melhor se desenvolva a aprendizagem. Ainda salienta Masseto apud Siqueira (2004) que o "sucesso (ou não) da aprendizagem está fundamentado essencialmente na forte relação afetiva existente entre alunos e professores $[\ldots] ”$.

Outros fatores responsáveis para a satisfação identificada nos relatos foram às relações interpessoais dos professores com os colegas de trabalho, um dado também presente nos resultados obtidos na pesquisa de Folle et. al. (2008) e Krug (2008). Os professores de Educação Física revelaram em sua quase totalidade que por conta da socialização com os colegas de trabalho se sentem mais satisfeitos profissionalmente.

[...] aqui na nessa escola se trabalha de uma maneira muito aberta, a gente faz muitas reuniões, então as coisas que tem que ser ditas elas são ditas nas reuniões pra todo mundo com todo mundo, e eu acho que isso faz o bem estar do grupo [...] (Professora 04).

As relações humanas são decorrentes do processo de interação compartilhadas por duas ou mais pessoas. Entre os indivíduos no espaço de trabalho, geralmente são estabelecidas pela necessidade da troca de informações sobre o exercício profissional, interesses pessoais e entre outros.

Para Codo (1999), as boas relações sociais são importantes em qualquer tipo de trabalho onde convivam duas ou mais pessoas no mesmo ambiente, ligadas diretamente pela mesma atividade. Ainda, afirma ele que criar um suporte social no trabalho pode vir a gerar satisfação, melhores possibilidades de lidar com atritos e situações estressantes, bem como melhorar a qualidade no trabalho dos profissionais envolvidos.

Os relacionamentos interpessoais entre colegas de profissão podem tornar o ambiente de trabalho mais harmonioso e prazeroso desde que também possam permitir ao funcionário sentir-se à vontade para expor suas potencialidades e que seja reconhecido por 
isso.

Outro motivo para a satisfação facilmente identificado nos depoimentos foi o trabalho docente em si. Esse dado não foi observado nos resultados dos estudos citados anteriormente.

[...] me sinto satisfeito pelo fato de trabalhar no que gosto [...] (Professor or).

[...] porque sou apaixonada pela minha profissão [...] (Professora or).

Para Lapo (2008), o trabalho dos professores em si comporta componentes essenciais para que se obtenha satisfação a partir de sua realização.

Esses componentes dizem respeito às características das várias tarefas que compõem o trabalho docente e que, em conjunto, propiciam ao professor um trabalho não rotineiro e não monótono; demandam o uso de diversas habilidades que, mesmo sendo diferenciadas, não são dissonantes entre si; permitem o "desligamento" dos problemas cotidianos; o sentimento de liberdade de escolhas e de controle sobre o processo de trabalho (p.II).

Afirma, ainda, o autor que o trabalho docente é "fonte de prazer e bem estar" (p.2). O estado de bem-estar pode oferecer aos professores condições mais favoráveis para lidar com conflitos e dificuldades profissionais, e também com as possibilidades de reestruturação adequada de suas práticas e modos de ser e estar na profissão (p.II).

As características que fazem da atividade docente uma atividade potencialmente geradora de bem-estar, para ele, são as seguintes:

[...] ter uma diversidade de tarefas que têm identidade entre si e que colocam desafios para quem as realiza, possibilitar o uso da criatividade, um certo grau de autonomia e o desenvolvimento de novas habilidades, exigir um alto grau de concentração, alterar a percepção do tempo e ser passível de auto-avaliação (p.II).

Outro dado presente nos relatos do docente, e que não foi observado em nenhum estudo citado anteriormente, foi a satisfação vinculada ao sentimento de reconhecimento do trabalho realizado por todos da comunidade escolar.

[...] até quando as pessoas vêm te dizer que o trabalho está bom, que não esperavam, sabe, aquilo tudo ali te trás uma satisfação bem grande [...] (Professora 07).

Nem sempre é só o aumento salarial que deixa o professor contente e satisfeito com sua profissão. O reconhecimento pelo trabalho realizado também provoca um sentimento de bem-estar que influencia diretamente seu trabalho.

Além disso, o reconhecimento profissional de forma positiva é muito importante, pois faz com que o profissional se sinta notado e valorizado. Segundo Leite (s.d), devemos 
saber reconhecer as capacidades, potencialidades, os méritos e as qualidades de nossos colegas de trabalho, pois dessa maneira conseguimos desenvolver verdadeiramente a cooperação e criar ambientes de trabalho mais saudáveis.

Foi destacado nos relatos do professores, como motivo para a sua satisfação, o esporte como conteúdo da Educação Física. Esse dado também esteve presente na pesquisa de Silva e Krug (2007).

[...] a gente pode passar pra criança através do esporte a educação. (Professor or).

É sabido que a prática esportiva tem importância significativa para as aulas de Educação Física, quando os alunos aprendem, por meio do esporte, a união, o respeito, a amizade, entre outros valores fundamentais que se deve levar para a vida. No entanto, não deve ser o único conteúdo a constituir um programa de educação física escolar.

Segundo Vago (1996), nos últimos 50 anos o esporte vem se transformado no principal, se não o único, conteúdo de ensino da Educação Física nas escolas. Salienta o autor que essa situação é decorrente da influência de uma prática cultural de esporte muito presente na sociedade, que visa atender a múltiplos interesses.

O problema principal é que esse esporte incorporado à cultura escolar produz unicamente uma prática de esporte abalizando o rendimento e desempenho do aluno. Isso demonstra a submissão da Educação Física escolar às regras da instituição esportiva, caracterizando o esporte na escola como um prolongamento dessa instituição.

Contrário a essa subordinação aos princípios da instituição esportiva, deve se compreender a Educação Física como:

[...] uma pratica pedagógica que, no âmbito escolar, tematiza formas de atividades expressivas corporais como: jogo, esporte, dança, ginástica, formas estas que configuram um área de conhecimento que podemos chamar de cultura corporal." (COLETIVO DE AUTORES, 1992, p. so)

Esses autores apontam que os temas da cultura corporal devem abordar os problemas da realidade, de modo que os alunos estabeleçam vínculos concretos com projetos políticos de mudanças sociais.

\section{CAPÍTULO III: A EDUCAÇÃO FÍSICA E A INSATISFAÇÃO COM O EXERCÍCIO PROFISSIONAL}

Assim como manifestaram sentimentos de satisfação quanto ao exercício profissional, os professores de Educação Física da Secretaria Municipal e Estadual de 
Educação da cidade de Pelotas - RS (Brasil) também demonstraram um sentimento de insatisfação com a profissão. Do mesmo modo que diversos são os motivos que apontam para a satisfação profissional, também outros tantos são referidos para a insatisfação.

Como nos resultados obtidos dos estudos de Folle et. al. (2008), Conceição et. al. (2009), Krug (2008), Silva e Krug (2007), os professores entrevistados, em sua quase totalidade, enfatizaram de forma negativa as condições de trabalho das escolas públicas, principalmente quanto à infraestrutura (espaço físico, quadra e material de trabalho).

[...] se tu fores avaliar as condições de trabalho que a gente tem são muito ruins, aqui na escola mesmo o espaço físico que a gente tem é muito ruim pra trabalhar com os alunos $[\ldots .$.$] (Professora or).$

[...] as escolas de um modo geral não são preparadas pra educação física, não foram, é um pátio com uma quadra [...] meus alunos agora tanto na parte da manhã quanto na parte da tarde, coitados, fico com pena, procuram a sombra das árvores [...] (Professor 03).

[...] normalmente as escolas compram materiais de segunda linha porque é mais barato; o custo benefício pra eles que estão gastando bem menos; mas pra gente por mais que eles comprem bola de segunda mão, material de 2 o mão em seguida ele destrói (Professor or).

As escolas públicas, no geral, não contam com os melhores recursos para o ensino, mas no mínimo contam com instalações básicas como salas de aulas equipadas com carteiras para os alunos, quadro-negro, etc., para as disciplinas de matemática, português, entre outras. Para a disciplina de Educação Física, em algumas escolas, às vezes, não se tem nem o mínimo, pois quando não são precárias as condições de trabalho, são inexistentes.

Trata-se de uma disciplina que tem uma demanda por espaço, instalações e materiais peculiares, desse modo, a falta desses elementos interfere de modo significativo na prática pedagógica.

É comum observar a aula de Educação Física no pátio de uma escola e ver os alunos jogando bola e o professor ao lado apenas observando a prática. O professor constrói um modo de abandonar a função de ensinar, apesar de continuar no seu posto de trabalho. Para Santini e Neto (2005) essa diminuição do envolvimento nas atividades docentes revela uma forma estratégica de o professor escapar momentaneamente das situações que causam estresse em seu trabalho, bem como a falta de condições para executá-lo.

Outro sentimento de insatisfação identificado, vinculado às condições de trabalho, foi a extensa carga horária, a qual os deixam sem tempo para a realização de outras tarefas. 
Esse dado não foi observado em nenhum estudo citado anteriormente.

[...] a única coisa assim que eu acho que ainda não tá legal pra mim assim é trabalho muito pra conseguir ganhar um pouquinho melhor entendeu, [...] a nossa hora aula é muito baixa acaba que a gente trabalha um monte pra poder ganhar um pouquinho melhor (Professora o6).

[...] com uma carga horária puxada eu não tenho praticamente nenhuma folga nunca (Professor 2).

[...] se trabalha muito hoje pra tu fazeres um salário mais ou menos, tu tens que trabalhar sessenta horas [...] aí pra tu ganhar um salário aí de mil e quinhentos reais, que compra uma casa própria, que te dê um carrinho, [...] se não, tu não paga nada não ganha nada (Professor 03).

O trabalho dos professores vai além do ato de ensinar, excede os limites da sala de aula, com a realização de atividades de preparação de aula, avaliações ou atendimentos de alunos e pais. As precárias condições de trabalho, principalmente, quanto à questão salarial, têm levado os professores a aumentar ainda mais sua carga de serviço.

A má remuneração que obriga o professor a atuar em grandes jornadas de trabalho cansativas e complexas, tem levado os profissionais a uma condição de sobrecarga de trabalho.

Segundo Garcia et. al. [200-] a sobrecarga pode comprometer a qualidade do trabalho e ter "reflexos diretos sobre a saúde dos profissionais, pois as altas cargas de atuação exigem grandes esforços emocionais e intelectuais dos professores para a realização das tarefas de trabalho" (p.4).

Ainda salientam que as excessivas horas de trabalho também diminuem as oportunidades para o desenvolvimento profissional, pois a formação, que continua por meio de cursos de atualização, acaba ficando afetada à medida que o tempo é um componente escasso para esses profissionais. Afirmam os autores, "com altas jornadas de trabalho semanal só resta a muitos desses professores esperar o passar dos anos para evoluir profissionalmente [...]" (p.3).

O enorme número de aulas pode não só comprometer a qualificação continuada e a saúde do professores, como também as possibilidades de descanso, lazer e de qualidade de vida. As exigências cotidianas e as metas a serem atingidas num período curto de tempo, entre outros, ocasionam aos professores não terem tempo nem para cuidarem de si próprios.

Foi observada também, quase em todas as respostas dos sujeitos da pesquisa, a questão salarial muito citada pelos professores como um elemento de descontentamento. 
Este dado, do mesmo modo, foi observado na pesquisa de Conceição et. al. (2009), Krug (2008), Silva e Krug (2007).

[...] agora até pra comprar um tênis é difícil, é complicada a coisa [...] (Professora or).

[...] é muito mal remunerado, isso me entristece, me entristece, 6oo pila não tem fundamento [...] (Professora 05).

Para Codo (1999) os professores são trabalhadores inseridos em uma sociedade dita capitalista, então, dessa forma, vendem sua força de trabalho e o preço que custa esse trabalho (remuneração) deve ser igual ao preço que custa para a manutenção e reprodução desta mesma força.

Entretanto, ele observa que os salários recebidos pelos docentes não está de acordo com o esforço realizado, pois o trabalho vai além da sala de aula com a preparação de atividades, correções de provas, entre outros, e nem por isso há uma compensação financeira ou mesmo o reconhecimento social merecido. $O$ salário do educador às vezes não paga nem as contas básicas do mês.

O autor afirma que o "dinheiro não compra felicidade“, mas define um padrão de vida com qualidade, no qual irá se refletir na possibilidade de menos privações, mais lazer, mais conforto pessoal e para os familiares, bem como a aquisição de recursos necessários para manter o seu conhecimento "passível de ser utilizado no mercado” (p.193). O salário não deve só ser adequado para suprir as necessidades, mas também para manter um bom padrão de vida.

Outro dado relatado pelos professores entrevistados indicou a indisciplina dos alunos como fator causador da insatisfação com a profissão. Dados também relatados por professores no trabalho de Krug (2008) e Silva e Krug (2007).

[...] tem alunos ótimos, às vezes tem uma turma que tem trinta e cinco alunos, trinta e dois ótimos, mas tem três alunos que tu fica todo tempo só cuidando deles [...] (Professora 04).

[...] falta de interesse dos próprios alunos então tudo tem que ser na insistência na goela a baixo, aí complica [...] (Professora 07).

De acordo com Aquino (2003) a indisciplina escolar deixou de ser, ao longo dos anos, um fenômeno eventual no cotidiano das escolas do Brasil para se tornar uma das maiores barreiras para o trabalho pedagógico dos dias de hoje.

Trata-se de um evento que não ocorre somente em instituições educativas públicas, como salienta o autor, "escolas particulares ou públicas podem ser alvos, em 
mesma intensidade, de contratempos disciplinares" (AQUINO, 2003, p.9). Os atos indisciplinados podem ocorrer em qualquer escola e por todas as fases da vida escolar, independente das características dos alunos.

O que se sabe é que não existe um perfil de professores predisposto a enfrentar situações de indisciplina dos alunos, pois o fenômeno não tem correlação com a metodologia empregada, nem com os conteúdos, nem ao gênero, idade, orientação sexual, situação economia e etnia do professor.

Para Aquino (2003), a indisciplina pode ser compreendida de várias maneiras, uma delas é pelo fenômeno típico da adolescência, no qual as pessoas tendem a fazer questionamento das regras e dos valores ditos pelos adultos. Também é compreendida como uma manifestação contra as figuras de autoridade ou das más influências do mundo virtual (TV, computador, jogos, etc.).

Outra compreensão para atos indisciplinados é a falta de estrutura familiar (separação dos pais, ausência na vida pessoal e escolar dos filhos, entre outros) ou o modo como as crianças e os jovens vêm sendo criados por seus familiares.

A indisciplina precisa ser neutralizada, pois influencia atos perigosos como a “ociosidade, violência, drogas, sexo irresponsável, etc.”. Os métodos mais adequados devem respeitar uma ordem, começando por um aconselhamento incansável, seguido de punições reparatórias, "e, como último recurso, um encaminhamento parapedagógico 7 " (AQUINO, 2003, p.I2).

A relação interpessoal entre professor e colegas de trabalho, assim como na pesquisa de Krug (2008), foram outro indicador de desagrado à profissão bastante presente nas falas dos professores. Os entrevistados alegaram que não há reconhecimento do trabalho, pelos colegas.

[...] os colegas não valorizam muito porque eles acham que é muito fácil então eles não, eles debocham, eu não dou a mínima bola porque eu acho a minha disciplina a mais importante porque sem a minha todos seriam muito tristes (Professora 05).

As relações de trabalho são influenciadas constantemente pelas relações interpessoais. $\mathrm{Na}$ escola, na maioria das vezes, a relação entre o professor e colegas de

\footnotetext{
7 È a especialidade da Conscienciologia dedicada ao estudo da educação abordando o processo pedagógico de forma integral, holossomática, multidimensional e multisserial. É subcampo científico da Comunicologia. Disponível em: 〈http://pt.conscienciopedia.org〉. Acesso: 22 Dez. 2009.
} 
trabalho se torna negativa pelo pouco diálogo estabelecido e pela falta de conhecimento sobre a importância da área de atuação de cada um. Segundo Beresford et. al. (2002), a falta de um trabalho interdisciplinar entre os professores também prejudica as relações dentro da escola, pois, dessa maneira, se torna difícil conhecer e valorizar o trabalho do outro.

É comum grande parte dos professores de Educação Física escolar, principalmente, vivenciarem conflitos nas relações com seus colegas de serviço, pois geralmente a disciplina não é rotulada por todos como indispensável ao desenvolvimento integral do aluno. Sem conhecer a Educação Física e sua importância, os professores de outras disciplinas e a administração da escola parecem ficar por conta de seus respectivos imaginários e, fundamentalmente, pela influência do que se observa e se ouve falar. Diz Beresford et. al. (2002), que a área da Educação Física sempre sofreu com a dificuldade de definir o seu papel dentro da sociedade

Desse modo, os professores de Educação Física sentem-se desvalorizados, o que vem prejudicar a satisfação profissional, pois, salienta Ramos e Spgolon (2005, p. 202 apud KRUG, 2008), "que a valorização profissional é de certo modo um incentivo, para qualquer profissional trabalhar com satisfação".

Diante disso, alguns estudos apontam que professor de Educação Física precisa se tornar um dos principais, se não o principal, agente transformador dessa realidade. É preciso mudar esta idéia reduzida e estereotipada que a comunidade escolar tem com relação à sua disciplina. A Educação Física necessita “ [...] tornar-se consciente da abrangência de seu trabalho, ocupando o espaço que lhe cabe na área educacional [...]” (BERESFORD et. al., 2002, p.II).

Cabe, inclusive, à equipe gestora da escola, diminuir estes abismos entre os profissionais, demonstrando, por meio de ações, como é necessária a valorização das relações na escola e como elas podem ser significativas.

As relações estabelecidas na escola podem gerar satisfação nos docentes e, dessa maneira, contribuir para o sucesso do ensino. Afirma silva (2008) que um dos fatores para o sucesso escolar está diretamente relacionado ao clima existente no ambiente escolar, ou seja, depende muito das relações interpessoais de todos os envolvidos com a prática educativa. 


\section{CONCLUSÃO}

$\mathrm{Na}$ análise que fizemos sobre a satisfação profissional de professores de Educação Física, na prática escolar de algumas escolas municipais e estaduais da cidade de Pelotas, localizadas na região sul do RS (Brasil), constatou-se que em relação aos estudos já realizados sobre esse tema, alguns dados se repetiram e outros não.

Nessa pesquisa, observou-se que o sentimento de satisfação com a profissão está ligado à importância do esporte como conteúdo da Educação Física e do trabalho docente em si, juntamente com as relações escolares do dia-a-dia, como a relação professor-aluno e professor-colegas, e ao sentimento de reconhecimento pelo trabalho realizado.

A insatisfação está, geralmente, vinculada à falta de adequadas condições para realizar um bom trabalho, ou seja, infraestrutura, materiais apropriados, agravados, ainda, pela extensa carga horária, baixos salários, indisciplina e falta de interesse dos alunos, e a relação interpessoal entre professor e colegas de serviço.

Conclui-se que no exercício profissional nem tudo causará satisfação, ou total insatisfação; muitos serão os fatores envolvidos na complexidade desses dois sentimentos, (aliás, como em todas as profissões) comprovando uma de nossas hipóteses.

Cabe salientar que foram observados, nessa pesquisa, outros dados que não foram constatados nos estudos anteriores citados neste trabalho. Para a satisfação com a profissão encontramos fatores vinculados ao trabalho docente em si e ao sentimento de reconhecimento pelo trabalho realizado. Como fator causador da insatisfação, foi observada a extensa carga horária de trabalho desses professores.

Por fim, esse trabalho contribui para a reflexão acerca da satisfação profissional docente na área da Educação Física, buscando resgatar elementos importantes para a discussão da qualidade no ensino, podendo também ser ampliado para outras áreas.

\section{REFERÊNCIAS BIBLIOGRÁFICAS}

AQUINO, J.G. Indisciplina: o contraponto das escolas. I ${ }^{a}$ Ed. São Paulo: Moderna, 2003.

BERESFORD, H; FONSECA, M. M; CODEA, J.S.M.T; CODEA. A.L de B. Uma visão sobre o valor da Educação Física curricular, a partir de perspectivas imaginárias e ideológicas. Rev. Paul. Educ. Fís., São Paulo, I6(I): Ioo -I2 jan./jun. 2002. Disponível em: 〈http://www.usp.br>. Acesso: ig Dez. 2009. 
CODO, W. Educação: carinho e trabalho. Petrópolis, RJ: Vozes, 1999.

COlETIVO DE AUTORES. Metodologia de ensino de educação física. São Paulo, Cortez, 1992, I19p.

CONCEIÇÃO, V. J. S. COSTA, R.R. KRUG, H.N. Professor de Educação Física Escolar no ensino fundamental: análise da realidade na cidade de Meleiro, SC. Revista Digital Buenos Aires - Ano I4 - № 135 - Agosto de 2009. Disponível em: 〈http://www.efdeportes.com〉. Acesso em: 13 Dez. 2009.

DERLANDES, S. F.; GOMES, R; MINAYO, M. C. S. Pesquisa social: teoria, método e criatividade. $25^{\mathrm{a}}$ Ed. Revista e atualizada. Petrópolis, RJ: Vozes, 2007.

FOLlE, A.; BORGES, L. J.; COQUEIRO, R. S.; NASCIMENTO, J. V. Nível de (In) satisfação profissional de professores de Educação Física da Educação Infantil. Motriz, Rio Claro, v.I4 n.2 p.I24-134, abri./jun.2008. Disponível em:〈http://cecemca.rc.unesp.br〉. Acesso em: ro jul. 2009.

GARCIA, P. S; MALACARNE, V; BIZZO, N. Formação Inicial, Atuação e Condições de Trabalho de Professores de Ciências: Estudo Exploratório em duas Regiões Brasileiras. Disponível em: $\langle$ http://www.fae.ufmg.br $>$. Acesso em: 20 Dez. 2009.

GATTI, B. A formação de professores e carreira: problemas e movimentos de renovação. Campinas: Autores Associados, 1997.

GUIA DAS PROFISSÕES. Realização profissional. Você sabe o que é isso?. Disponível em: 〈http://www.guiadasprofissoes.com.br〉. Acesso em: 13 Dez. 2009.

KRUG, H. N. Vale a pena ser professor de Educação Física escolar?. Revista Digital Bueno Aires - Ano 13 - $\mathrm{N}^{\circ}{ }_{122}-$ Julio de 2008. Disponível em: 〈http://www.efdeportes.com>. Acesso em: ro jul. 2009.

LAPO, F. R. Bem-Estar Docente. 2008. Disponível em: 〈http://www.fae.ufmg.br >. Acesso em: 28 Dez. 2009.

LEITE, L. Saber Reconhecer o Mérito do Outro. Disponível em: 〈http://www.profissionaldesucesso.com.br〉. Acesso em: 12 Dez. 2009.

MINAYO, M. C. de S. Pesquisa social: teoria, método e criatividade. $25^{\underline{a}}$ Ed. Revista atualizada. Petrópolis, RJ: Vozes, 2007.

MORETTI, S. Qualidade de Vida no Trabalho X Auto-Realização Humana. Disponível em: 〈http://www.icpg.com.br>. Acesso em: 13 Dez. 2009.

SANTINI, J. NETO, V. M. A síndrome do esgotamento profissional em professores de educação física: um estudo na rede municipal de ensino de Porto Alegre. Rev. bras. Educ. 


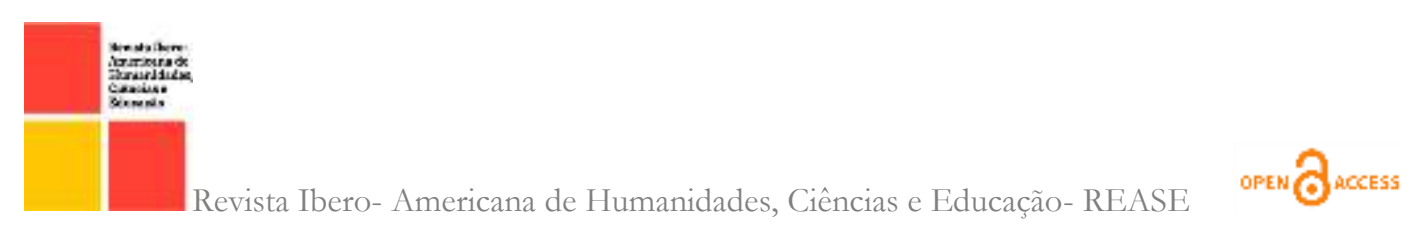

Fís. Esp., São Paulo, v.19, n.3, p.209-22, jul./set. 2005. Disponível em: < http://www.usp.br/>. Acesso em: 13 Dez. 2009.

SILVA, E. Relações Interpessoais no Ambiente Escolar. Em Extensão, Uberlândia, v. 7, n. 2, p. Iо - I8, 2008.

SILVA, M. S. KRUG, H. N. Os sentimentos satisfação e insatisfação dos professores de Educação Física. Revista Digital - Buenos Aires - Ano 12 - $\mathrm{N}^{\circ}{ }_{115}$ - Dezembro de 2007. Disponível em: 〈http://www.efdeportes.com>. Acesso em: i3 Dez. 2009.

SIQUEIRA, D. de C. T. Relação Professor - Aluno: Uma Revisão Crítica. 2004. Disponível em: 〈http://www.conteudoescola.com.br〉. Acesso em: 13 Dez.20o9.

VAGO, Tarcísio Mauro. O "esporte na escola” e o "esporte da escola”: Da negação radical para uma relação de tensão permanente - um diálogo com Valter Bracht. Movimento, ano III, n. 5, p. 4-I7, 1996/2. 